\title{
Stimulation of endocytosis in mouse blastocysts by insulin: a quantitative morphological analysis
}

\author{
G. F. Dunglison ${ }^{1,2 *}$, S. D. Jane ${ }^{3}$, T. F. McCaul ${ }^{4}$, J. E. Chad ${ }^{3}$, \\ T. P. Fleming ${ }^{2}$ and P. L. Kaye ${ }^{1 \dagger}$ \\ ${ }^{1}$ Department of Physiology and Pharmacology. The University of Queensland, Brisbane, Queensland 4072, \\ Australia; ${ }^{2}$ Department of Biology and ${ }^{3}$ Department of Physiology and Pharmacology, School of Biological \\ Sciences, The University of Southampton, Southampton SO16 7PX, UK; and ${ }^{4}$ Centre for Microscopy and \\ Microanalysis, The University of Queensland, Brisbane, Queensland 4072, Australia
}

\begin{abstract}
The effects of insulin on the endocytic activity of mouse blastocysts in vitro were investigated using confocal laser scanning microscopy, quantitative image analysis and electron microscopy. Confocal studies showed that fluorescein isothiocyanate-labelled markers, dextran (fluid phase) and albumin (combined membrane and fluid phase), were endocytosed by blastocysts and localized within vesicles (about $2.5 \mu \mathrm{m}$ in diameter) in the outer trophectoderm cells. No labelling was detected in the inner cell mass cells or the blastocoel cavity. Treatment with $170 \mathrm{nmol}$ insulin $1^{-1}$ stimulated the endocytosis of fluorescently labelled dextran in freshly collected blastocysts, increasing mean vesicle diameter per embryo by $15 \%(P<0.05)$ after incubation with insulin for $2.5 \mathrm{~h}$ and mean vesicle number per embryo by $56 \%(P<0.01)$ after $6 \mathrm{~h}$. Both effects were also evident in blastocysts that had been cultured from the late eight-cell stage. Blastocysts incubated for $6 \mathrm{~h}$ with insulin displayed increased convolutions in the trophectoderm apical membrane compared with controls, indicating increased membrane activity and suggesting macropinosome formation. Collectively, these results suggest that insulin enhances endocytosis in the trophectoderm by stimulating uptake at the apical membrane into larger and more numerous endocytic vesicles and with some evidence of vesicle fusion. This mechanism may provide a metabolic basis for the stimulation by insulin of biosynthesis, proliferation and morphological development in early embryos.
\end{abstract}

\section{Introduction}

After fertilization, mouse embryos develop to blastocysts of about 125-250 cells before implantation, late on day 4 of gestation. During this period, the developing embryo is free in the oviduct or uterus and must rely on endogenous stores or components of the fluids of the reproductive tract to meet the various requirements of cell proliferation and differentiation. Overt differentiation commences at the eight-cell stage, leading to the formation of two fundamental cell lineages of the blastocyst, the outer epithelial trophectoderm and the inner cell mass (ICM; reviewed in Fleming, 1992). The fetus develops from the ICM, while the trophectoderm cells give rise to non-fetal components (reviewed in Gardner, 1983).

Mouse embryos take up nutrients by different mechanisms, depending upon nutrient size and charge. Small solutes such as amino acids, glucose and pyruvate, use specific transport systems for their uptake (Kaye, 1986; Gardner and Leese, 1988; Van Winkle, 1988). However, large molecules such as proteins

*Current address: Department of Human Morphology, Queen's Medical Centre, The University of Nottingham, Nottingham, NG7 2UH, UK.

Correspondence.

Received 28 March 1995.

are available to the embryo only by receptor-mediated endocytosis (Heyner et al., 1989; Smith et al., 1993), endocytosis of protein in the fluid phase or nonspecific adsorption to the cell membrane (Fleming and Pickering, 1985; Fleming and Goodall, 1986; Pemble and Kaye, 1986). The fluids of the reproductive tract are rich sources of protein (Gardner and Leese, 1990); the operation of the latter endocytic pathway may therefore be of great nutritional potential to the developing embryo.

Embryos developing in vivo endocytose BSA injected into the maternal circulation, suggesting that maternal serum proteins are taken up by nonspecific endocytosis (Glass, 1963). Using uptake of radioiodinated BSA in vitro, Pemble and Kaye (1986) observed a large increase in endocytic activity at blastocyst formation, reaching a rate of fluid uptake equivalent to $2.5 \%$ of the total blastocyst volume per minute. This surge in endocytic activity at the blastocyst stage coincides with the time at which the trophectoderm endocytic apparatus matures and becomes spatially organized such that endocytosis occurs preferentially from the outer (apical) membrane (Fleming and Pickering, 1985; Fleming and Goodall, 1986). Thus, as the embryo differentiates, its endocytic system becomes a highly active conduit for maternally derived nutrient uptake to support early growth and development. 
In many cell types, the activity of the endocytic system and of the plasma membrane may be influenced by hormones and growth factors, such as insulin (Brunk et al., 1976; Haigler et al., 1979; Kadowaki et al., 1986; Miyata et al., 1988). Blastocyst physiology responds to insulin with stimulation of protein synthesis, mitogenesis and morphological development (Harvey and Kaye, 1988, 1990; Heyner et al., 1989; Rao et al., 1990; Gardner and Kaye, 1991; Kaye et al., 1992; Kaye and Harvey, in press) and in particular, an increased rate of endocytosis of radiolabelled BSA (Dunglison and Kaye, 1993) and dextran (Dunglison and Kaye, 1995).

In view of these findings, and to gain a better understanding of the mechanism of this increased activity, we have quantified the morphological effects of insulin on endocytosis in mouse blastocysts using confocal and electron microscopy.

\section{Materials and Methods}

\section{Embryo collection}

All experiments were approved by the Institutional Animal Ethics Committee as conforming to NHMRC guidelines. Female Quackenbush (Gore Hill Research Laboratory, University of Technology, Sydney; 4-5 weeks old) or MF1 mice (Olac-derived, Southampton University Animal House; 3-4 weeks old; used for fluorescein isothiocyanate (FITC) dextran labelling confocal studies) were superovulated by i.p. injection of 5-10 iu pregnant mares' serum gonadotrophin (Folligon, Intervet, North Ryde and Cambridge) at 10:00 h or 14:00 h, respectively, and 5-10 iu hCG (Chorulon, Intervet) $48 \mathrm{~h}$ later. The mice were then paired overnight with individual males of the same breed. The presence of a vaginal plug the next morning indicated mating. Embryos were recovered by flushing oviducts and uteri at the late eight-cell stage $(72 \mathrm{~h}$ after hCG injection) or the mid-blastocyst stage ( $96 \mathrm{~h}$ after hCG injection) in medium 2 (M2; Fulton and Whittingham, 1978). Blastocysts used for FITC dextran studies were cultured in medium 16 (M16; Whittingham, 1971) under oil at $37^{\circ} \mathrm{C}$ and $5 \% \mathrm{CO}_{2}$ in air. Late eight-cell embryos were cultured under the same conditions for approximately $20 \mathrm{~h}$ until they had formed blastocysts. Blastocysts used for FITC albumin or ultrastructural studies were cultured in BMOC2 (Brinster, 1965; modified as described by Hobbs and Kaye, 1985) under oil at $37^{\circ} \mathrm{C}$ in an atmosphere of $5 \% \mathrm{CO}_{2}, 5 \% \mathrm{O}_{2}, 90 \% \mathrm{~N}_{2}$. Unless noted otherwise, M2 and M16 both contained $4 \mathrm{~g} \mathrm{BSA} \mathrm{I}^{-1}$; and BMOC2 contained $1 \mathrm{~g} \mathrm{BSA} \mathrm{I}^{-1}$.

\section{Fluorescence labelling}

Freshly collected blastocysts $(96 \mathrm{~h}$ after hCG injection; blastocoel cavity occupying approximately half of the blastocyst volume) were incubated in M16 containing $12.5 \mathrm{~g}$ FITC dextran $1^{-1}\left(9.4 \times 10^{3} M_{\mathrm{r}}\right.$; Sigma Chemical Company, St Louis, $\mathrm{MO})$ or BMOC2 containing $12.5 \mathrm{~g}$ FITC BSA $\mathrm{I}^{-1}$ $\left(67 \times 10^{3} \mathrm{M}_{\mathrm{r}}\right.$ Sigma Chemical Company) at $37^{\circ} \mathrm{C}$ or $4^{\circ} \mathrm{C}$ for $2 \mathrm{~h}$, collected and washed four times in $\mathrm{M} 2$ at $25^{\circ} \mathrm{C}$, before fixation in $2 \%(\mathrm{w} / \mathrm{v})$ paraformaldehyde in PBS, $\mathrm{pH} 7.4$ for $1 \mathrm{~h}$. After collecting and washing four times in PBS, the blastocysts were transferred in a minimal volume of PBS to poly-L-lysine coated coverslips within immunolabelling chambers. Coverslips were placed on top of the chambers to prevent the drying of embryos. Three control and three insulin-treated blastocysts were placed in the same immunolabelling chamber and visualized using confocal microscopy.

Embryos were incubated in M16 in the presence or absence of $170 \mathrm{nmol}$ insulin $1^{-1}$ (Humulin R, Eli Lilly, Basingstoke) at $37^{\circ} \mathrm{C}$ for $20 \mathrm{~h}$ (eight-cell embryos) or $0.5,2$ and $4 \mathrm{~h}$ (blastocysts), transferred to the same medium containing FITC dextran at $37^{\circ} \mathrm{C}$ for $2 \mathrm{~h}$ labelling, and then processed for confocal studies as described above.

\section{Confocal microscopy and image analysis}

FITC-labelled embryos were visualized using a BioRad MRC 600 Series Confocal Imaging System equipped with an argon ion laser producing an excitation wavelength of $488 \mathrm{~nm}$. This system permitted the imaging of individual optical planes of intact blastocysts without out-of-focus contamination. Confocal settings were standardized for insulin-treated and control embryos (confocal aperture set at 4; black level set at zero light). A series of optical sections (12 per embryo, each approximately $3 \mu \mathrm{m}$ thick) was recorded at $5 \mu \mathrm{m}$ intervals throughout the $z$ axis, using a Nikon Fluor $\times 10$ lens (numerical aperture $=0.5$ ) with an electronic zoom of $\times 8$ and a theoretical resolution of $0.6 \mu \mathrm{m}$. Each series of sequential $z$ sections was processed to determine the maximum intensity value for each $x, y$ coordinate (effectively collapsing the $z$ dimension), and this information was used to calculate an extended focus image (PZ series) of the labelled areas throughout the blastocyst. The labelled areas were resolved into 256 grey levels of fluorescence intensity and the images presented in pseudocolour to emphasize the differences in fluorescence intensity. Smaller groups of sections for the embryo surface (sections 1-3) and midplane (sections 7-9) were also used.

Analysis of the diameters and number of endocytic vesicles in control and insulin-treated blastocysts was performed using the Interactive Biological Analysis System (IBAS; Kontron Electronik Ltd, St Albans). Binary images of the stored confocal images ( $\mathrm{PZ}$ series and smaller summed sections) were produced using the confocal software, to extract features from the background. These were captured on colour slide film and scanned into a video camera. An IBAS evaluation program was then used to analyse the number and diameters of vesicles in each image.

For each blastocyst, the IBAS provided a value for the total number of vesicles per blastocyst and a corresponding mean vesicle diameter per blastocyst $\left(x_{i}\right)$. A mean vesicle diameter \pm SEM was then determined for 10-12 blastocysts per treatment as follows:

$$
\text { mean }=\Sigma n_{\mathrm{i}} x_{\mathrm{i}} / \Sigma n_{\mathrm{i}}
$$

where $n_{\mathrm{i}}=$ number of vesicles per blastocyst and $x_{\mathrm{i}}=$ mean vesicle diameter per blastocyst.

$$
\begin{gathered}
\text { variance, } s^{2}=\left[\sum n_{\mathrm{i}} x_{\mathrm{i}}^{2}-\left(\sum n_{\mathrm{i}} x_{\mathrm{i}}\right)^{2} / \Sigma n_{\mathrm{i}} / /\left(\sum n_{\mathrm{i}}-1\right)\right. \\
\operatorname{SEM}=\sqrt{ } s^{2} / \Sigma n_{\mathrm{i}}
\end{gathered}
$$

As each PZ series was composed of approximately 12 sections, each $3 \mu \mathrm{m}$ thick and about $5 \mu \mathrm{m}$ apart through the 

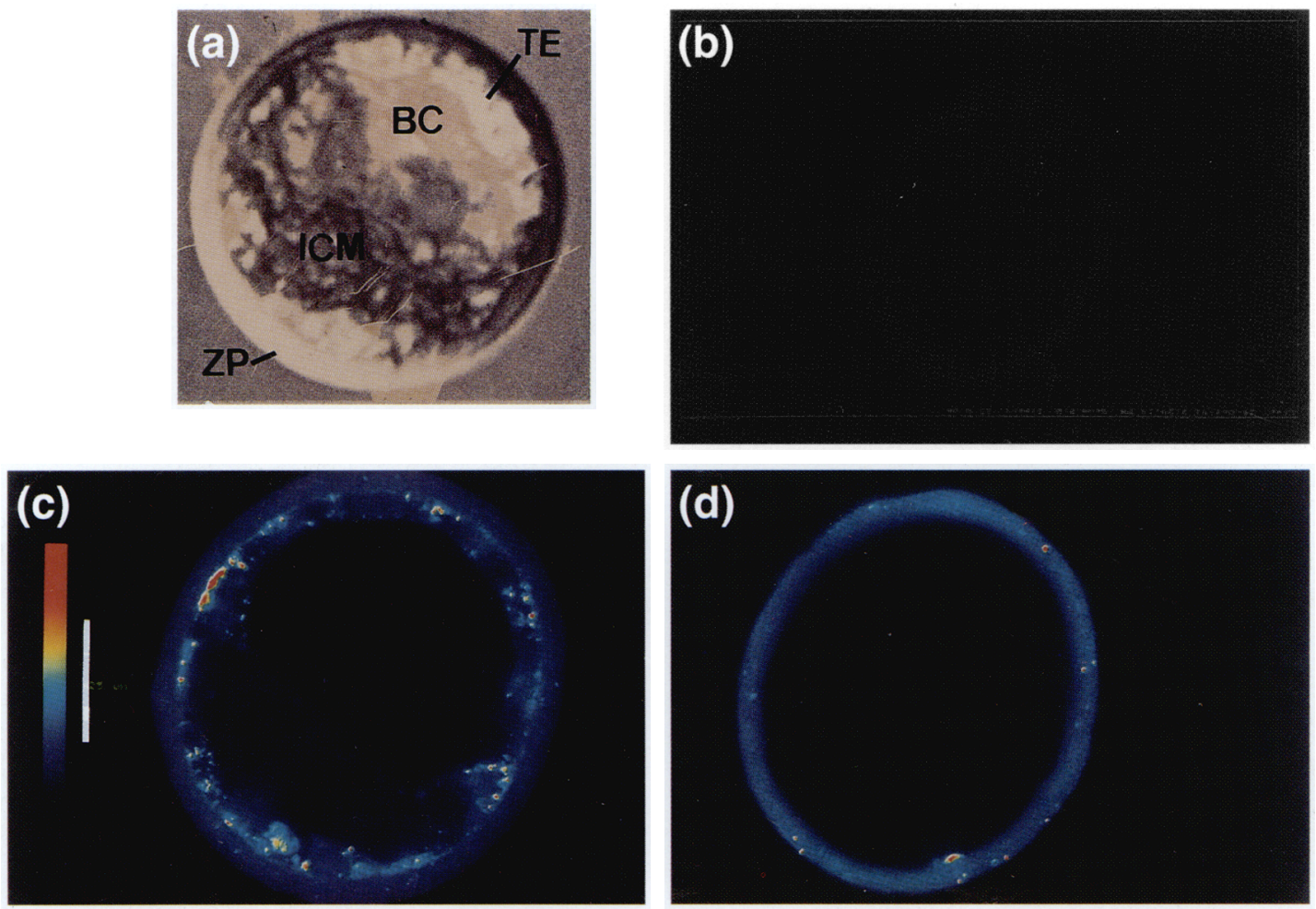

Fig. 1. (a) Confocal transmission image of a blastocyst. TE: trophectoderm; ICM: inner cell mass; BC: blastocoel cavity; ZP: zona pellucida. (b-c) Pseudocoloured confocal images displaying equatorial sections $(\approx 3 \mu \mathrm{m})$ of (b) blastocysts incubated in MI6 containing $12.5 \mathrm{~g}$ FITC dextran $\mathrm{I}^{-1}$ at $4^{\circ} \mathrm{C}$, (c) blastocysts incubated in BMOC2 containing $12.5 \mathrm{~g}$ FITC albumin $1^{-1}$ at $37^{\circ} \mathrm{C}$ and (d) at $4^{\circ} \mathrm{C}$ for $2 \mathrm{~h}$. Red represents high, and blue low fluorescence intensity. Scale bar represents $25 \mu \mathrm{m}$.

embryo (i.e. a total thickness scanned of approximately $36 \mu \mathrm{m}$ ) and the average diameter of blastocysts fixed to the chambers was $60 \pm 0.82 \mu \mathrm{m}$, the number of vesicles counted per blastocyst should be multiplied by the factor $60 / 36$, to present the total number of labelled vesicles in the blastocysts accurately.

\section{Statistical analysis}

Statistical analysis of the differences between control and insulin-treated blastocysts was performed by Student's $f$ test.

\section{Electron microscopy}

Freshly collected blastocysts ( $96 \mathrm{~h}$ after hCG injection) were incubated in $\mathrm{BMOC} 2$ in the presence or absence of $170 \mathrm{nmol}$ insulin $1^{-1}$ at $37^{\circ} \mathrm{C}$ for $6 \mathrm{~h}$, collected, washed extensively in M2 and placed onto fibroblast monolayers, which had been grown on Thermanox coverslips (Nunc Inc., IL) and exposed to $0.04 \mathrm{~g}$ phytohaemagglutinin (L9017; Sigma Chemical Company) $\mathrm{I}^{-1}$ in M2 (Wiley et al., 1985). The coverslips with attached embryos were flooded with $3 \%(\mathrm{w} / \mathrm{v})$ glutaraldehyde in 0.066 mol cacodylate $\mathrm{I}^{-1}$ buffer, $\mathrm{pH} 7.2$ at $25^{\circ} \mathrm{C}$, and left at this temperature for $30 \mathrm{~min}$ before fixation was completed at $4^{\circ} \mathrm{C}$ overnight. After washing with 0.066 mol cacodylate $\mathrm{I}^{- \text {- }}$ buffer containing $0.15 \mathrm{~mol}$ sucrose $1^{-1}, \mathrm{pH} 7.2$, the embryos were post-fixed with $1 \%(\mathrm{w} / \mathrm{v})$ osmium tetroxide in $0.066 \mathrm{~mol}$ cacodylate $\mathrm{I}^{-1}$ buffer, $\mathrm{pH} 7.2$, before embedding in Spurr's resin (Spurr, 1969). Sections were cut at $70 \mathrm{~nm}$ on a Nova ultramicrotome (LKB, Bromma), using a diamond knife (Diatome Ltd, Biene), and stained with $0.5 \%(\mathrm{w} / \mathrm{v})$ uranyl acetate in $50 \%(\mathrm{v} / \mathrm{v})$ ethanol and lead citrate (Reynolds, 1963), before examining in a Hitachi H800 electron microscope operated at $100 \mathrm{kV}$. Control and insulin-treated blastocysts were compared by viewing up to ten sections per blastocyst from 3-4 blastocysts per treatment over three experiments.

\section{Results}

\section{Confocal microscopy}

Blastocysts (see Fig. 1a for blastocyst morphology) incubated with FITC dextran for $2 \mathrm{~h}$ at $37^{\circ} \mathrm{C}$ revealed staining of endocytic vesicles in the trophectoderm, but not in the ICM or blastocoel cavity (Fig. 2f). No labelling of cells with FITC dextran was apparent at $4^{\circ} \mathrm{C}$ (Fig. 1b). At $37^{\circ} \mathrm{C}$, the pattern of labelling with FITC albumin was similar to that with FITC dextran (Fig. 1c), although at $4^{\circ} \mathrm{C}$ FITC albumin was evident in the zona pellucida (Fig. Id), a result never observed with FITC dextran.

In freshly collected blastocysts exposed to insulin for up to $6 \mathrm{~h}$, there was a marked increase in the intensity of FITC dextran labelling of trophectoderm vesicles (Fig. 2a, f). Analysis of the effect of treatment with insulin for $2.5-6.0 \mathrm{~h}$ on mean vesicle diameter and number per embryo performed on PZ 


\section{CONTROL}
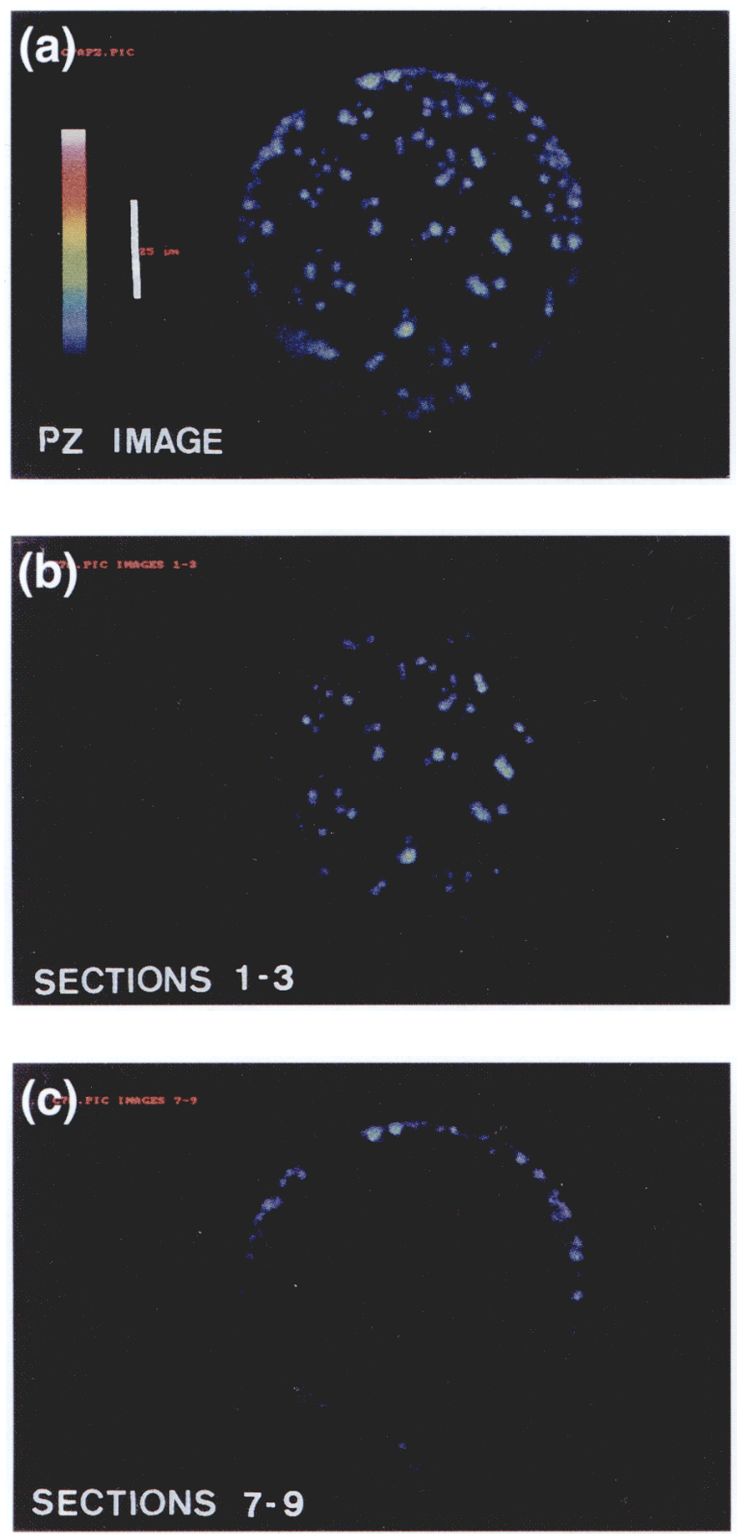

INSULIN
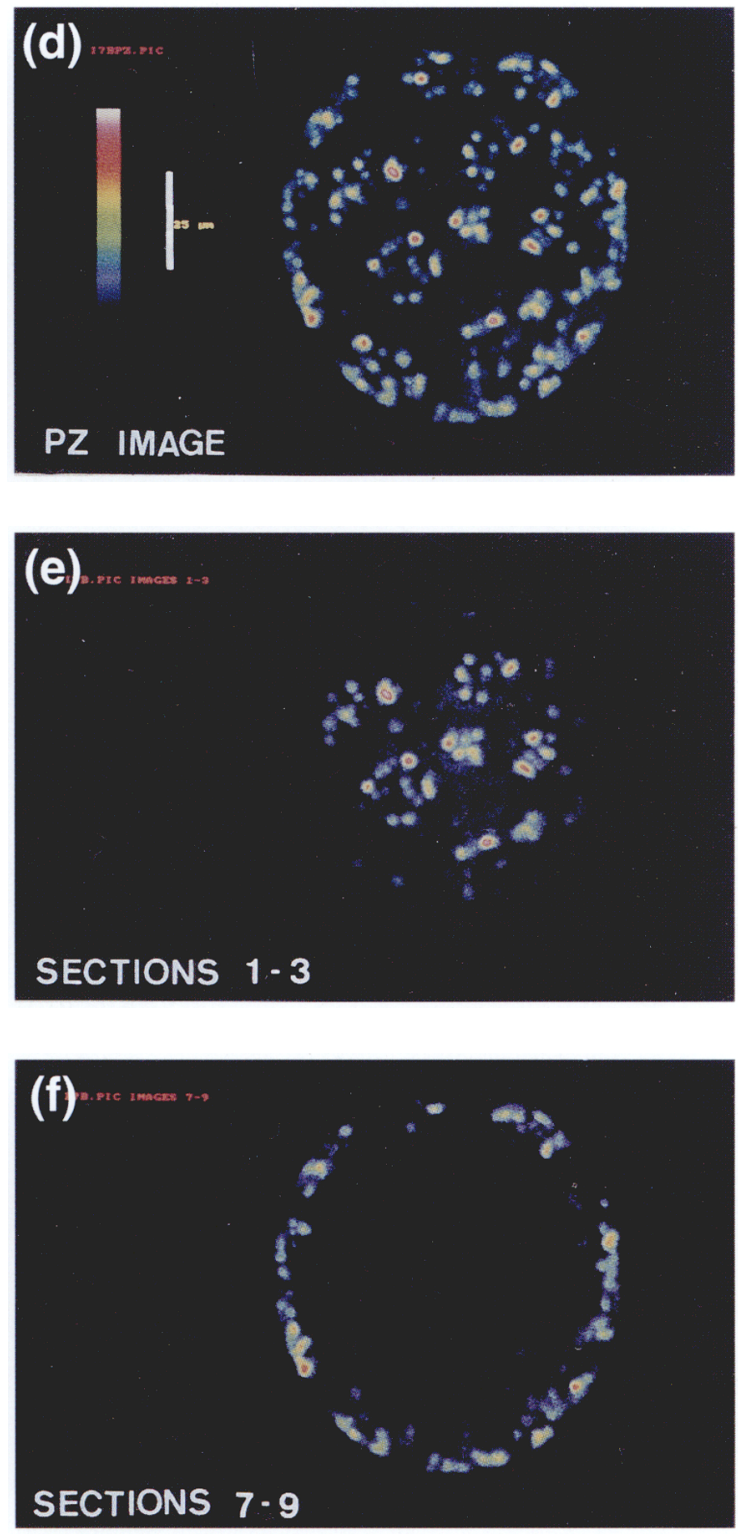

Fig. 2. Pscudocoloured confocal images of ( $a, d) P Z$ series; (b, e) sections $1-3$ (surface region); and (c, f) sections 7-9 (midplane region) imagres of blastocysts that had been incubated at $37^{\circ} \mathrm{C}$ in $\mathrm{M} 10$ (a-c) or $\mathrm{M} 16$ containing 170 nmol insulin I $\mathrm{l}$ ( $d-f$ ) for $4 \mathrm{~h}$, and then transferred to the same medium containing $12.5 \mathrm{gFITC}$ dextran $\mathrm{l}^{-1}$ at $37^{\circ} \mathrm{C}$ for $2 \mathrm{~h}$. Red represents high and blue low fluorescence intensity. Scale bar represents $25 \mu \mathrm{m}$.

series, surface region (sections $1-3$ ) and midplane region (sections 7-9) images of control and insulin treated blastocysts (Fig. 3), showed that in control blastocysts, as the culture period increased from $2.5 \mathrm{~h}$ to $6 \mathrm{~h}$, mean vesicle diameter per embryo decreased slightly, while mean vesicle number per cmbryo decreased more substantially (Fig. 3). Data from control blastocysts cultured from the late eight-cell stage were similar to those observed for blastocysts after control incubation for $6 \mathrm{~h}$ (Fig. 3).

Insulin treatment generally increased mean vesicle diameter per embryo in the PZ series and both surface and midplane section series, on average by $15 \%(P<0.05$; Fig. 3a). This was evident in both freshly collected blastocysts and blastocysts cultured for $22 \mathrm{~h}$ from the late eight-cell stage. In contrast, after incubation with insulin for $2.5 \mathrm{~h}$, the mean number of vesicles per embryo was reduced by $25 \%(P<0.01)$ in the PZ scries (Fig. 3b). However, by $4 \mathrm{~h}$, more vesicles were present in insulin-treated than in control blastocysts in both $\mathrm{PZ}$ and section images, and this rose to $56 \%(P<0.0 I)$ in the $\mathrm{PZ}$ and midplane series $(P<0.01)$ after exposure to insulin for $6 \mathrm{~h}$. Culture of late eight-cell embryos to the blastocyst stage in insulin produced a 30\% ( $P<0.01)$ and $55 \%(P<0.001)$ increase in mean number of vesicles per embryo in the $\mathrm{PZ}$ and surface series, respectively, compared with controls (Fig. 3b). 
(a)
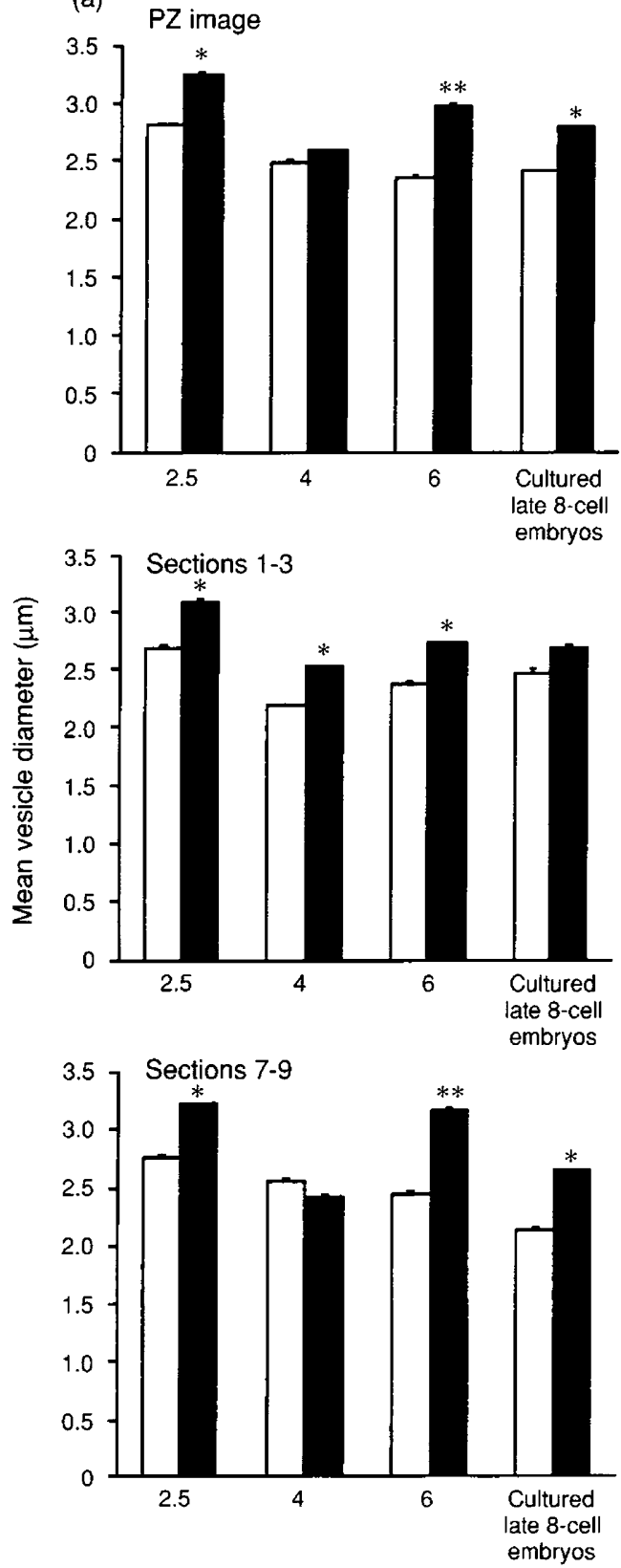

(b)
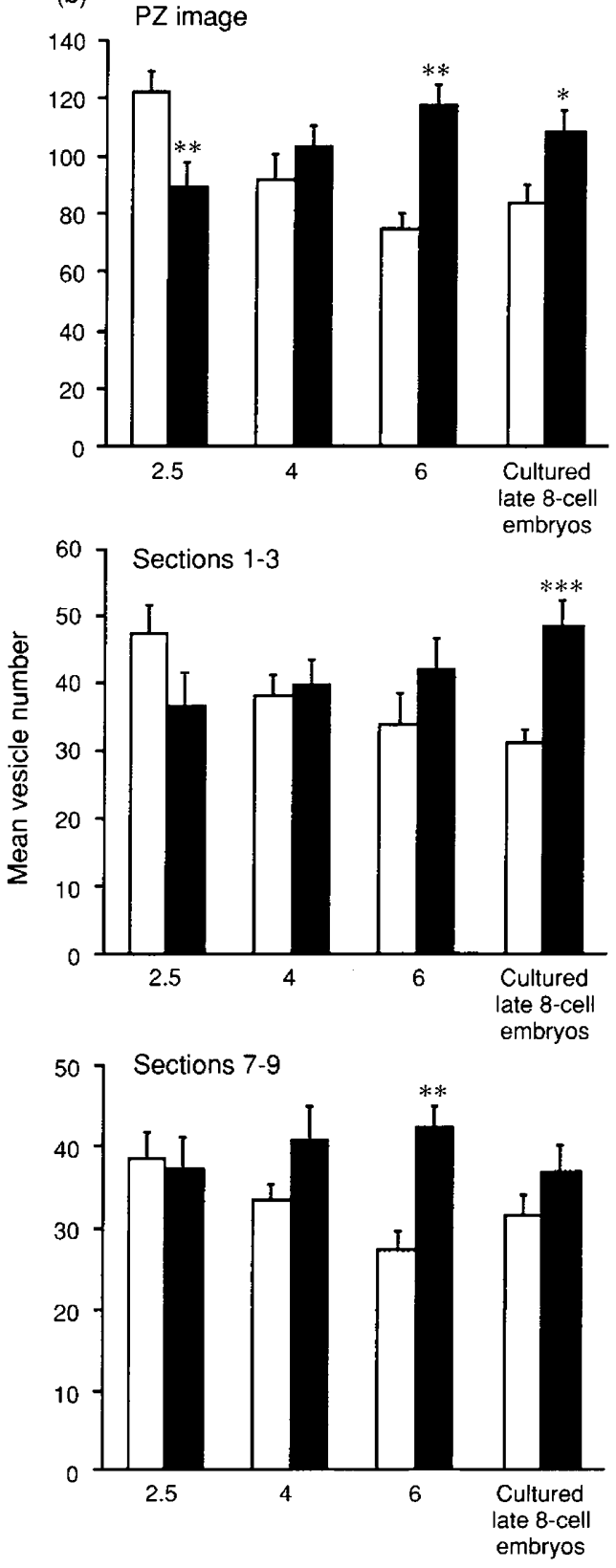

Time ( $h$ )

Fig. 3. Temporal effects of insulin ( $\mathbf{D}$ ) on (a) vesicle diameter and (b) number of vesicles per embryo in PZ series, sections I-3 and 7-9 of confocal images of blastocysts incubated in M16 in the presence or absence of $170 \mathrm{nmol}$ insulin $1^{-1}$ at $37^{\circ} \mathrm{C}$ for $2.5,4$ and $6 \mathrm{~h}$. (口) Control values. Labelling with $12.5 \mathrm{~g}$ fluorescein isothiocyanate (FITC) dextran $\mathrm{I}^{-1}$ occurred in the last $2 \mathrm{~h}$ of the incubation period. Late eight-cell embryos were cultured under the same conditions for $22 \mathrm{~h}$, before reaching the blastocyst stage. Blastocysts, fresh and cultured, were then collected, washed and fixed for confocal microscopy and image analysis. Each data point represents the mean $\pm \mathrm{SEM}, n=10-12$ embryos, 5- 6 embryos per treatment per experiment. Significantly different from control $\left.{ }^{*} P<0.05 ; * * P<0.01 ; * * P<0.001\right)$.

\section{Electron microscopy}

Compared with controls, blastocysts that had been pretreated with insulin for $6 \mathrm{~h}$ showed increased membrane convolutions at the apical surface of trophectoderm cells, manifested as 'ruffling' of the cell membrane and finger-like projections extruding from the membrane surface (Fig. 4). Some projections appeared to fold back or collapse towards the membrane, possibly owing to the restriction in movement imposed by the zona pellucida, suggesting the formation of 

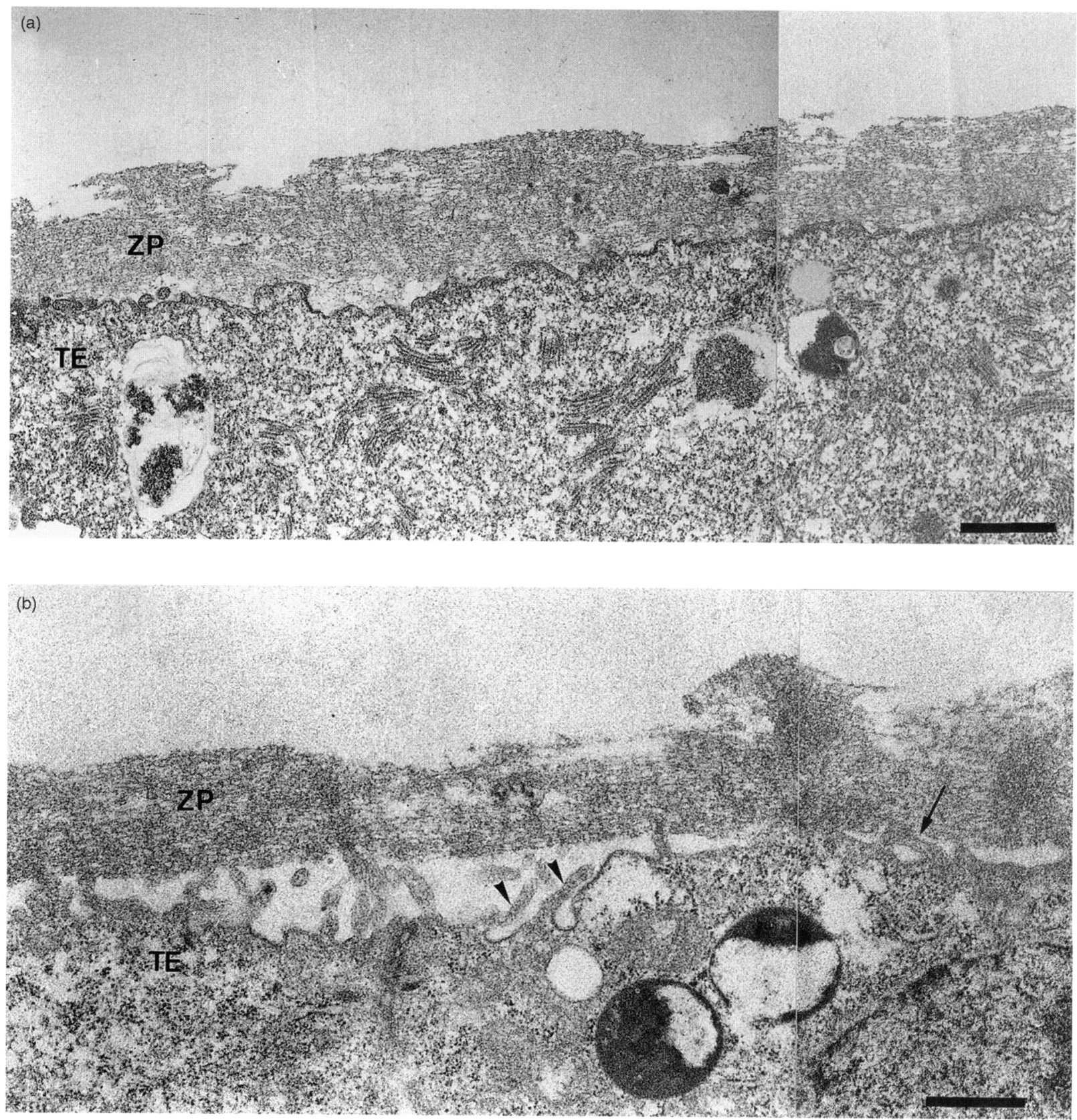

Fig. 4. Trophectoderm (TE) membrane activity in (a) control and (b) insulin-treated blastocysts. Blastocysts were cultured in BMOC2 with and without $170 \mathrm{nmol}$ insulin $\mathrm{I}^{-1}$ at $37^{\circ} \mathrm{C}$ for $6 \mathrm{~h}$, and then collected and prepared for electron microscopy using conventional methods. Arrowheads indicate the formation of finger-like projections that have folded towards the trophectoderm membrane (TE), and the arrow indicates possible macropinosome formation. ZP: zona pellucida. Scale bar represents $1 \mu \mathrm{m}$.

large vesicles or macropinosomes. Perhaps because of this ruffling, the zonae pellucidae of insulin-treated blastocysts were not as closely apposed to the trophectoderm plasma membrane as those of control blastocysts.

\section{Discussion}

In this study, we have used confocal fluorescence microscopy combined with a morphometric image analysis programme and electron microscopy, to characterize and quantify the effect of insulin on endocytosis in mouse blastocysts. One consistent observation, whether using the fluid phase marker, FITC dextran, or the combined membrane and fluid marker, FITC albumin, was that labelling occurred exclusively in the outer trophectoderm cells of the blastocyst. Uptake of the two fluorescent markers was inhibited at low temperature, but at $37^{\circ} \mathrm{C}$, both displayed a punctate distribution, typical of cytoplasmic vesicles, in the trophectoderm. After incubation for $2.5 \mathrm{~h}$, the labelled sites were $2.5-3.0 \mu \mathrm{m}$ in diameter, which is 
consistent with the size of multivesicular bodies and lysosomes in confocal images, but is possibly overestimating true diameter by about $1 \mu \mathrm{m}$, because of the optics of the confocal system. These size estimates are in agreement with those of earlier microscope studies of blastocysts (Chisholm et al., 1985; Fleming and George, 1987) and support those from earlier studies on embryos of rats (Schlafke and Enders, 1973), rabbits (Hastings and Enders, 1974), mice (Fleming, 1986; Fleming and Goodall, 1986; Pemble and Kaye, 1986; Dunglison and Kaye, 1993, 1995) and sheep (Pullar et al., 1990). Collectively, they demonstrate that the mammalian trophectoderm engages in active endocytosis of external fluid, not only for direct transcytosis, but also for lysosomal breakdown and the supply of low molecular weight nutrients to support other embryonic processes in both the trophectoderm and possibly ICM tissues, after release to the blastocoel. Confocal microscopy showed albumin, but not dextran, binding to the zona pellucida, particularly at $4^{\circ} \mathrm{C}$; this is consistent with albumin being an adsorptive and fluid phase marker, and dextran being a fluid phase marker.

Insulin treatment significantly increased the overall intensity of FITC dextran-labelled vesicles in the trophectoderm, which could be explained either by (i) a higher concentration of the marker within vesicles of the same size and frequency, or (ii) more fluid present within larger vesicles or an increased number of vesicles per unit volume. In (i), a higher concentration could be achieved by increased membrane binding before endocytosis but, for FITC dextran, there is no evidence that surface binding takes place. These possibilities were analysed by quantifying the mean vesicle diameter and number of vesicles per blastocyst from PZ series and section images of insulin-treated and control blastocysts. The analysis showed that in freshly collected blastocysts exposed to insulin for $2.5-6 \mathrm{~h}$, there was a significant increase of $15 \%$ in mean vesicle diameter $(P<0.05)$. This increase was not distorted by vesicle 'overlap' in the PZ series, as it was also apparent in the surface and midplane series (Sections $1-3$ and $7-9$ in Fig. 3). In addition, insulin caused a significant increase of $56 \%(P<0.01)$ in number of vesicles per embryo in the $\mathrm{PZ}$ and midplane series images, but only after incubation for $6 \mathrm{~h}$.

The increase in trophectoderm vesicle diameter and number after insulin treatment probably explains the overall increase observed in vesicle intensity. These data together with our analysis of insulin stimulation of uptake of ${ }^{125}$ I-labelled BSA (Dunglison and Kaye, 1993) and $\left[{ }^{3} \mathrm{H}\right]$ dextran (Dunglison and Kaye, 1995) lead to the conclusion that insulin acts on the endocytic apparatus in trophectoderm to stimulate the internalization of surrounding fluid.

The increase in vesicle diameter could represent a membrane phenomenon whereby the size of pinocytic vesicles pinching off from the apical surface is increased. This has been observed in macrophages after stimulation with phorbol ester (Swanson, 1989), and in human carcinoma A431 cells in response to epidermal growth factor (Haigler et al., 1979). Alternatively, the increase in vesicle diameter could reflect a cytoplasmic event where vesicle fusion is enhanced, possibly leading to larger multivesicular bodies or lysosomes. This activity has also been observed in macrophages after growth factor stimulation (Swanson et al., 1987; Nilsson et al., 1989). In this case, the number of vesicles would decrease proportionally with vesicle fusion. Consistent with this, analysis of our data showed that after insulin treatment for $2.5 \mathrm{~h}$, mean vesicle diameter was significantly increased, while the number of vesicles was significantly lower than in controls. However, extensive morphometric analysis of endosomes, multivesicular bodies and lysosomes in electron microscopy sections is required to confirm this.

After longer incubations with insulin, mean vesicle diameter and number of vesicles were both increased compared with controls. Here, cytoplasmic vesicle fusion alone cannot explain the results, and increased membrane activity is implicated. In the ultrastructural analysis, insulin treatment appeared to increase trophectoderm apical membrane convolutions, and irregular fluctuations and finger-like projections were frequently apparent. In some cases, these projections appeared to fold back on themselves, resembling the formation of macropinosomes. This may be a direct effect of insulin to increase pinocytic activity at the surface, or simply due to the constriction by the zona pellucida. Furthermore, other pathways, including coated and uncoated pits and cavaeolae, may contribute to macropinosome formation after long-term treatment with insulin. Further ultrastructural morphometric studies are required to confirm this observation, but it lends support to our conclusion that the increased vesicle fusion alone cannot explain the increased size and number of vesicles present in blastocysts after exposure to insulin for longer. Membrane ruffling leading to macropinosome formation has been observed after growth factor stimulation of various cell types (Brunk et al., 1976; Bar-sagi and Feramisco, 1986; Kadowaki et al., 1986; Miyata et al., 1988). Taken together, our confocal, ultrastructural and kinetic data (Dunglison and Kaye, 1993, 1995) suggest that, from $6 \mathrm{~h}$ onwards, insulin stimulates trophectoderm membrane activity and micropinosome formation, leading to an increased uptake of endocytosed fluid and membranes localized within larger and more numerous endocytic vesicles compared with controls. Similar stimulations in mean vesicle diameter and number per embryo were obtained for blastocysts that had been cultured from the late eight-cell stage. However, embryos exposed to insulin in long-term culture also show stimulated mitogenesis (Harvey and Kaye, 1990) and morphological development (Gardner and Kaye, 1991), so that the effects of insulin on endocytic activity in cultured embryos may also relate to its influence on other embryonic processes.

In the absence of insulin, blastocysts that were cultured for $4 \mathrm{~h}$ or longer showed a gradual, slight decline in the diameter and number of lysosomal bodies; this indicated that culture conditions may retard endocytic activity, which is consistent with their effects on other embryonic processes (Bowman and McLaren, 1970; Anderson and Foote, 1975; Turner et al., 1992, 1994). These effects appear to be eliminated in the presence of insulin, supporting the conclusions of the beneficial effects of this growth factor on blastocyst development in vitro (Kaye et al., 1992).

Mouse reproductive tract fluids contain $10 \mathrm{~g}$ protein $\mathrm{l}^{-1}$ (Gardner and Leese, 1990), which is likely to provide a major source of amino acids for protein synthetic processes after endocytic uptake and lysosomal hydrolysis. As this report shows, insulin, also present in utero (Heyner et al., 1989), stimulates this process considerably, increasing the delivery of 
protein and other macromolecular nutrients to support cell proliferation, differentiation and blastocyst expansion. The separate contributions of fluid phase and membrane bound components to the endocytosis of albumin have been assessed, using radiolabelled tracers, to be about equal at $10 \mathrm{~g} \mathrm{l}^{-1}$, delivering a total of about $3.4 \mathrm{ng} \mathrm{h}^{-1}$ (Dunglison and Kaye, 1995). If mouse uterine albumin resembles human serum albumin and contains 14 glycine residues per molecule, the fluid phase endocytosis visualized in this study would deliver about $300 \mathrm{fmol}$ glycine $\mathrm{h}^{-1}$ to the blastocyst as albumin. This is about $10 \%$ of that available through amino acid transport (Hobbs and Kaye, 1985), assuming uterine glycine concentrations are saturating and there is no competition by other uterine amino acids for uptake. Another factor is the potential of endocytosed albumin to carry such nutrients as $\mathrm{Cu}^{2+}$, fatty acids, sterols and tryptophan. These data reveal the potential nutritional role of maternal proteins, embryonic endocytosis and lysosomal activity for the preimplantation embryo.

The authors thank the National Health and Medical Research Council (NHMRC), Australia for the Biomedical Postgraduate Scholarship that supported G. F. Dunglison and the British Council for a Postgraduate Bursary to support her travel to T. P. Fleming's laboratory, where the combined confocal and image analyses were carried out. The research was also supported by project grants to P. L. Kaye from NHMRC, Australia and to T. P. Fleming from the Wellcome Trust, UK. The authors acknowledge the assistance of the Biosciences Imaging Group of Southampton University, funded by the MRC and the SERC, C. Macqueen with the CLSM in Brisbane, an Australian Research Council Large Equipment Grant, E. Adams with the IBAS computer analysis, M. Harvey with the ultrastructural studies, M. Hay, C. McFadden, K. Markham and E. Larsen.

\section{References}

Anderson GB and Foote RH (1975) Effects of low temperature on subsequent nucleic acid and protein synthesis of rabbit embryos Experimental Cell Research $9073-78$

Bar-sagi D and Feramisco J (1986) Induction of membrane ruffling and fluidphase pinocytosis in quiescent fibroblasts by ras proteins Science $\mathbf{2 3 3}$ 1061-1068

Bowman P. and McLaren A (1970) Viability and growth of mouse embryos after in vitro culture and fusion Journal of Embryology and Experimental Morphology $23693-704$

Brinster RL (1965) Studies on the development of mouse embryos in vitro 4. Interaction of energy sources Journal of Reproduction and Fertility 10 227-240

Brunk U, Schellens VJ and Westermark B (1976) Influence of epidermal growth factor on ruffling activity pinocytosis and proliferation of cultivated human glial cells Experimental Cell Research 103 295-302

Chisholm JC, Johnson MH, Warren PD, Fleming TP and Pickering S (1985) Developmental variability within and between mouse expanding blastocysts and their ICMs Journal of Embryology and Experimental Morphology 86 311-336

Dunglison GF and Kaye PL (1993) Insulin regulates protein metabolism in mouse blastocysts Molecular Reproduction and Development 36 42-48

Dunglison GF and Kaye PL (1995) Endocytosis in mouse blastocysts: characterisation and quantitation of the fluid phase component Molecular Reproduction and Development 41 225-231

Fleming TP (1986) Endocytosis and epithelial biogenesis in the mouse early embryo Bioassays 4 105-109

Fleming TP (1992) Trophectoderm biogenesis in the preimplantation mouse embryo. In Epithelial Organisation and Development pp 111-136 Ed. TP Fleming. Chapman and Hall, London
Fleming TP and George MA (1987) Fluorescent latex microparticles: a noninvasive short-term lineage marker suitable for use in the mouse early embryo Roux's Archives Development Biology 196 1-11

Fleming TP and Goodall H (1986) Endocytic traffic in trophectoderm and polarised blastomeres of the mouse preimplantation embryo Anatomical Record 216 490-503

Fleming TP and Pickering SJ (1985) Maturation and polarization of the endocytic system in outside blastomeres during mouse preimplantation development Journal of Embryology and Experimental Morphology 89 175-208

Fulton B and Whittingham DG (1978) Activation of mammalian oocytes by intracellular injection of calcium Nature 273 149-151

Gardner DK and Leese HJ (1988) The role of glucose and pyruvate transport in regulating nutrient utilisation by preimplantation mouse embryos Development 194 423-429

Gardner DK and Leese HJ (1990) Concentrations of nutrients in mouse oviduct fluid and their effects on embryo development and metabolism in vitro Journal of Reproduction and Fertility 88 361-368

Gardner HG and Kaye PL (1991) Insulin increases cell numbers and morphological development in mouse preimplantation embryos in vitro Reproduction Fertility and Development 3 79-91

Gardner RL (1983) Origin and differentiation of extraembryonic tissues in the mouse International Reviews in Experimental Pathology 124 63-133

Glass LE (1963) Transfer of native and foreign serum antigens to oviducal mouse eggs Journal of American Zoology 3 135-156

Haigler HT, McKanna JA and Cohen S (1979) Rapid stimulation of pinocytosis in human carcinoma cells A-43I by epidermal growth factor Journal of Cell Biology 83 82-90

Harvey MB and Kaye PL (1988) Insulin stimulates protein synthesis in compacted mouse embryos Endocrinology 122 1182-1184

Harvey MB and Kaye PL (1990) Insulin increases the cell number of the inner cell mass and stimulates morphological development of mouse blastocysts Development $110963-967$

Hastings RA and Enders AC (1974) Uptake of exogenous protein by the preimplantation rabbit Anatomical Record 179 311-330

Heyner S, Rao LV, Jarrett L and Smith RM (1989) Preimplantation mouse embryos internalise maternal insulin via receptor-mediated endocytosis pattern of uptake and functional correlations Developmental Biology $\mathbf{1 3 4}$ $48-58$

Hobbs JG and Kaye PL (1985) Glycine transport in mouse eggs and preimplantation embryos Journal of Reproduction and Fertility 74 77-86

Kadowaki T, Koyasu S, Nishida E, Sakai H, Takaku F, Yahara I and Kasuga M (1986) Insulin-like growth factors insulin and epidermal growth factor cause rapid cytoskeletal reorganization in KB cells Journal of Biological Chemistry 261 16141-16147

Kaye PL (1986) Metabolic aspects of the physiology of the preimplantation embryo. In Experimental Approaches to Mammalian Embryonic Development, pp 267-292 Eds J Rossant and R Pedersen. Cambridge University Press, Cambridge

Kaye PL and Harvey MB The role of growth factors in preimplantation development Progress in Growth Factor Research (in press)

Kaye PL, Bell KL, Beebe LFS, Dunglison GF, Gardner HG and Harvey MB (1992) Insulin and IGFs in preimplantation development Reproduction Fertility and Development 65 373-386

Miyata Y, Hoshi M, Koyasu S, Kadowaki T, Kasuga M and Hikoichi S (1988) Rapid stimulation of fluid-phase endocytosis and exocytosis by insulin-like growth factor- 1 and epidermal growth factor in KB cells Experimental Cell Research 178 73-83

Nilsson M, Nilsson K and Forsbeck K (1989) Increased endocytosis and formation of multivesicular bodies in phorbol ester-stimulated human monoblastic U-937 cells Experimental Cell Research 18155 I-565

Pemble LB and Kaye PL (1986) Whole protein uptake by mouse blastocysts Journal of Reproduction and Fertility $\mathbf{7 8}$ 149-157

Pullar D, Te Kronnie G, Dammika Peris I, Taverne N, Jeacock MJ, Stroband HWJ and Shepherd DAL (1990) Morphological and radiochemical evidence for the metabolism of exogenous proteins by the preimplantation sheep blastocyst Development 110 539-546

Rao LV, Wikarczuk ML and Heyner S (1990) Functional roles in preimplantation embryo development In vitro Cell and Developmental Biology 26 1043-1048

Reynolds ES (1963) The use of lead citrate at high $\mathrm{pH}$ as an electron-opaque stain in electron microscopy Journal of Cell Biology 17 208-212

Schlafke S and Enders AC (1973) Protein uptake by rat preimplantation stages Anatomical Record 175 539-560

Downloaded from Bioscientifica.com at 04/26/2023 02: 08:04PM 
Smith RM, Garside WT, Aghayan M, Shi C-Z, Shah N, Jarett L and Heyner S (1993) Mouse preimplantation embryos exhibit receptor-mediated binding and transcytosis of maternal IGF1 Biology of Reproduction 49 I-12

Spurr AR (1969) Immunocytochemical demonstration of serine pyruvate aminotransferase in peroxisomes and mitochondria of rat kidney Histochemistry $84381-85$

Swanson JA (1989) Phorbol esters stimulate macropinocytosis and solute flow through macrophages Journal of Cell Science 94 135-142

Swanson J, Bushnell A and Silverstein SC (1987) Tubular lysosome morphology and distribution within macrophages depend on the integrity of cytoplasmic microtubules Proceedings of the National Academy of Science USA 84 1921-1925
Turner K, Goldstein DJ and Rogers AW (1992) Variation in the dry mass of mouse embryos throughout the preimplantation period Human Reproduction 7 112-116

Turner K, Rogers AW and Lenton EA (1994) Effect of culture in vitro and organ culture on the dry mass of preimplantation mouse embryos Reproduction Fertility and Development 6 229-234

Van Winkle LJ (1988) Amino acid transport in developing animal oocytes and early conceptuses Biochimica et Biophysica Acta 947 173-208

Whittingham DG (1971) Culture of mouse ova Journal of Reproduction and Fertility Supplement 14 7-21

Wiley LM, Takaki KK and Yamagata M (1985) Electron microscopy of mouse preimplantation embryos and isolated blastomeres immobilised on coverslips Gamete Research 11 5I-58 